\title{
CORONARY ARTERY BYPASS GRAFTING IN PATIENTS WITH SEVERE LV DYSFUNCTION: EARLY RESULTS
}

Murtaza A. Chishti1 ${ }^{1}$ Ajay Meena ${ }^{2}$, Gaurav Goyal ${ }^{3}$, Premraj Nagarwal ${ }^{4}$, Varun Chhabra ${ }^{5}$, Ashish Jain ${ }^{6}$, Deepesh Aggarwal7, Ramanand D. Sinha ${ }^{8}$

\section{HOW TO CITE THIS ARTICLE:}

Murtaza A. Chishti, Ajay Meena, Gaurav Goyal, Premraj Nagarwal, Varun Chhabra, Ashish Jain, Deepesh Aggarwal, Ramanand D. Sinha. "Coronary Artery Bypass Grafting in Patients with Severe LV Dysfunction: Early Results". Journal of Evolution of Medical and Dental Sciences 2015; Vol. 4, Issue 86, October 26;

Page: 15063-15069, DOI: $10.14260 /$ jemds/2015/2137

ABSTRACT: BACKGROUND: Coronary artery disease with severe left ventricular dysfunction is always a challenge for surgeon and cardiologist. Previous reports showed high mortality (>50\%) for operations. Current studies favours surgical revascularization. MATERIALS AND METHODS AND RESULTS: Between Jan 2014 to June 2015 n=102 patients underwent coronary artery bypass grafting for coronary artery disease with severe left ventricular dysfunction at our centre. Severe left ventricular dysfunction was defined by ejection fraction less than $30 \%$ on two dimensional echocardiogram. Operative criteria for these patients were included preserved wall thickness, angina class III or IV, myocardium viability $>20 \%$ and good target vessels. Preoperative characteristics and outcomes were analysed. RESULTS: No early or late morbidity and mortality occurred. Significant improvement in ejection fraction and relief of angina $(\mathrm{p}<0.0055)$ was present. $83 \%$ operations were done off pump. CONCLUSION: Coronary revascularization is good option in patient with severe left ventricular dysfunction particularly patients with angina, good target vessels, preserved wall thickness and viable myocardium $>20 \%$. (Words-161).

KEYWORDS: Coronary Artery Disease, Left Ventricular Dysfunction.

INTRODUCTION: Coronary artery bypass grafting (CABG) in patients with poor left ventricular (LV) function remains a surgical challenge and cardiac transplantation may be the only alternative in some cases. Because of poor long-term survival and unsatisfactory results surgeons are still unsure as to the choice between medical and surgical options..$^{1-3}$ in early reports mortality was as high as $50 \%$ so surgical revascularization was not preferred. ${ }^{4}$ more recent studies reported lower mortality rates in surgical management of such patients. Myocardial revascularization in patients with severe LV dysfunction prevents further myocardial damage and induces the recovery. Few studies have shown that these patients benefit most from revascularization, if angina is present. ${ }^{5-6}$

MATERIALS AND METHODS: The study was conducted in the department of cardiothoracic and vascular surgery, department of cardiac anesthesia and department of cardiology. From January 2014 to June 2015 total 633 patient of coronary artery disease were operated out of which 102 patients had severe LV dysfunction. Severe left ventricular dysfunction was defined by ejection fraction on two dimensional echocardiogram of $30 \%$ or less. These patients were studied retrospectively. At our center selection criteria for surgery include angina, preserved LV wall thickness on two dimensional echocardiography, suitable target vessels and presence of $>20 \%$ viable myocardium on myocardial viability test. Patients with recent cardiac events were medically optimized prior to surgery. We studied the variables that might affect the outcome including age > 70 year, sex, angina class, left main disease, diabetes, smoking, hypertension and Renal Dysfunction. 
We looked at use of intra-aortic balloon counter pulsation, inotropic support, ICU stay, hospital stay, post op NYHA class after surgery and in follow-up. In the preoperative assessment diabetes was defined as receiving anti-diabetic medication or insulin for control of blood glucose level. Hypertension was defined as systemic arterial pressure $>140 / 90 \mathrm{mmHg}$ or usage of at least one antihypertensive medication. Renal failure was defined as serum Creatinine level $>1.5 \mathrm{mg} / \mathrm{dL}$. Early hospital mortality and late mortality terms were used to refer the deaths occurring within 30 days postoperatively and thereafter, respectively.

Operative Techniques: After standard anaesthesia induction procedure, a radial artery line, a femoral artery line and a Swan-Ganz catheter were inserted to monitor the systemic pressure, and the cardiac filling pressures. Intra-aortic balloon counterpulsation (IABP) was on standby. All operations were performed through median Sternotomy and Left internal mammary artery (LIMA) was used in all except one patient. Off pump CABG using a tissue stabilizer was our default technique. Criteria to go on pump was concomitant surgeries for other cardiac lesion, rhythm changes, rise in pulmonary artery pressure (systolic $>50$ ). Complete revascularization was aimed at in all cases.

Statistical Analysis: Statistical analyses were performed by SPSS/PC+ (ver. 11.5) computer program. The probability (p) less than 0.05 were considered significant. Frequency and \%values of categorical variables, and mean, average and standard deviation values of continuous variables were determined. Patient characteristics and hospital outcomes were compared by using t tests for continuous variables and chi-square or Fisher exact test for categorical variables.

\section{RESULTS:}

Demography and Clinical Characteristics: Of all 102 patients $84.3 \%(n=86)$ were male and 15.7\%

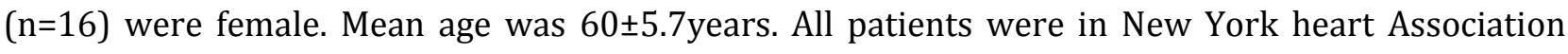
(NYHA) class III or IV. Out of these $48 \%$ patients were diabetic, $84 \%$ patients were chronic active smoker, 54\% patients were hypertensive and 36\% patients had all these three risk factors. Two patients had previous history of stroke with complete recovery. One patient had heart block and underwent temporary pacemaker outside with IABP preoperatively and underwent surgery after stabilization. Preoperative left main disease was present in $19 \%$ of patients. Echocardiographic ejection fraction (EF) assessed and mean EF was $27 \pm 2.66 \%$. Mean Preoperative hemoglobin level was $12 \pm 5 \mathrm{gm} \%$, preoperative renal function was normal in all patients except one. Preoperative mitral valve regurgitation was present in 41 patients (40\%), out of which 16 patients (15\%) had moderate mitral valve regurgitation and two patients had severe mitral valve regurgitation and both underwent mitral valve replacement. Cardiopulmonary bypass was used in 17 patients (beating heart surgery was done in 15 patient and two patients underwent surgery with arrested heart where mitral valve replacement was done. (Table 1).

Early Results: No hospital mortality occurred. No perioperative myocardial infarction (MI) \{defined by CK MB $>90 \mathrm{IU} / \mathrm{L}$ and the presence of a new $\mathrm{Q}$ wave in two derivations of electrocardiogram (ECG)\} observed. Two patients needed re-exploration for bleeding in postoperative period. None of our patient developed renal dysfunction postoperatively. One patient who had renal dysfunction had lower creatinine level in post-operative period and good urine output. Cardiac supportive drug used in immediate postoperative period includes noradrenaline, adrenaline and dobutamine. 
Out of 102 patients $69 \%$ of patient required inotropic support for less than 24 hour and only $27 \%$ patients required support for more than 48 hours. None of our patient required inotropic support after 96 hour of surgery. $71 \%$ of patient managed with only single inotropic support and only three cases required three inotropic support. Postoperative mean ICU stay was $3 \pm 1$ days. Mean postoperative hospital stay was $9.2 \pm 8$ days. Immediate post-operative hemoglobin was $9.6 \pm 2$ and $16 \%$ patients. Left internal mammary was used in all patients except one and bilateral mammary were used in one patient. Total $18.6 \%(\mathrm{n}=20)$ of patient developed atrial fibrillation in post-operative period. Post-operative echocardiography was done on day 6 which showed no deterioration in left ventricular function and mean EF was $35.3 \pm 3 \%$ after surgery and 67 patients (66\%) showed improvement in ejection fraction in post-operative period (Table 2 and 3).

Survival and Relief of Symptoms: In this study no early and late death occurred. Two patients were re-explored for bleeding. None of our patient developed renal failure or respiratory failure. Only complication which occurred in $18.6 \%$ patients was atrial fibrillation which was managed with drugs, we preferred amiodarone infusion and used cautiously in these patient. 16.8\% $(n=17)$ patient needed cardiopulmonary bypass for safe conduct of revascularization. All patients were angina free till last follow up. There was no cardiac event noticed in post-operative period. Echocardiographic evaluation showed significant improvement in ejection function in post-operative period $(p=0.0003)$.

Pre-operative all of our patients were in class III or IV while in post-operative period $92 \%$ of patients were in class II or I and this improvement was significant $(\mathrm{p}=0.0002)$. Echocardiographic assessment in post-operative period showed reduction of mitral regurgitation in 10 patients out of 16 patients who had moderate mitral regurgitation but it was not statistically significant. By multivariate analysis none of the preoperative factor showed any significant association with improvement in ejection fraction and angina.

DISCUSSION: Medical treatment of patients with CAD with severe LV dysfunction helps in certain extent but carries a poor long term prognosis. Luciani.7 et al reported that patients with mean LVEF of $22 \%$, the 5 -year survival was just $28 \%$ with medical treatment. Louie and colleagues. ${ }^{8}$ reported a survival rate of less than $25 \%$ in 3 years. The alternative treatment like heart transplantation carries its own morbidity and mortality as well as donor availability and post-operative complications related to immunosuppressants. The Coronary Artery Surgery Study (CASS) reported that there was survival benefit for patients with LVEF $<26 \%$ who had a $43.5 \%$ 5-year survival with medical therapy versus $63 \%$ with surgery. ${ }^{9}$

Islamoglu et al. ${ }^{10}$ reported $5.16 \%$ of hospital mortality rate, and $78.57 \%$ of survival rate in 42.14 \pm 19.96 months of follow-up time. In their study they assess the effect of many factors on outcome and they found age $>70$ year, myocardial preservation techniques, NYHA class III or IV were some factors which affected the outcome.

At our center protocol is to assess first operability of such patients and we decide on the basis of presence of angina, target vessels, preserved myocardial wall thickness in echocardiography, left main disease and viable myocardium more than $20 \%$ on myocardial viability test. In such cases we preferred complete revascularization and we preferred off pump surgery to avoid CPB related complications. We aimed at complete revascularization. The indication for CPB mainly was hemodynamic instability, significantly rise in pulmonary artery pressure during cardiac manipulation and positioning and where an additional procedure like mitral valve replacement was needed. 


\section{ORIGINAL ARTICLE}

Atrial fibrillation which occurred in patients was managed with amiodarone.

Gatti et al.11 identified early predictors of mortality as prolonged invasive ventilation, acute renal injury and multiple blood transfusions. In our study major advantage was that most of our patient underwent surgery off pump and post-operative renal dysfunction was not a problem. Although we found that there was a drop in hemoglobin level but it was not associated with any morbidity or mortality and we prefer not to transfuse blood in postoperative period unless hemoglobin dropped below 8gms/dl.

Hospital stay was $9.2 \pm 2$ days. Many of our patients come from far flung areas and a few extra days in hospital are allowed for non-medical reasons.

Gatti et al and islamoglu et al showed significant improvement in ejection fraction and angina in postoperative period. We also found significant improvement in ejection fraction and relief of angina episodes in post-operative period and it was statically significant $p<0.0003$ and $<0.0002$ respectively.

Trachiotis and colleagues found that clinical predictors of mortality were older age, female sex, and diabetes, severity of angina class, hypertension, and CHF.12 Some of these factors correlated with poor survival, such as diabetes, hypertension, CHF and previous MI were also predictors of postoperative angina. ${ }^{12}$ Mickleborough and colleagues showed that predictors of decreased survival were advanced age, functional symptom class IV, and poorly visualized coronary vessels unsuitable for CABG. ${ }^{13}$ Argenziano and colleagues studied 900 randomized patients with LVEF 35\%, and identified that the presence of CHF symptoms as well as previous CABG were determinants of mortality, and advanced age, implantable cardioverter-defibrillator (ICD) implantation, and the presence and severity of CHF symptoms were determinants of increased length of stay in hospital.14

In our study none of preoperative characteristics were associated significantly with outcome. In conclusion, CABG should be considered in suitable patients with LV dysfunction because it considerably improves the LVEF and the functional capacity. In our study mitral valve regurgitation was also improved post-operatively. Off pump CABG is associated with low risk and low morbidity and mortality in such patients.

Limitations of the Study: This study was retrospective, the duration of follow-up of this study was somewhat more limited than those of some current multi-centre based trials. This is single centre, single surgeon study. It needs corroboration in a larger population with longer follow-up.

Follow up- follow up data is complete for all 102 patients. Until last follow up visit $92 \%$ of them were in NYHA functional class II or I.

\section{REFERENCES:}

1. Scott SM, Deupree HL, Sharma GVRK, Luchi RJ. VA study of unstable angina. 11-year results show duration of surgical advantage for patients with impaired ejection fraction. Circulation 1994; 90(Suppl 2): 120-3.

2. Pigott JD, Kouchoukos NT, Oberman A, Cutter GR. Late results of surgical medical therapy for patients with coronary artery disease and depressed left ventricular function. J Am Coll Cardiol 1985; 5: 1036-45.

3. DiCarli MF, Maddahi J, Rokhsar S, et al. Long-term survival of patients with coronary artery disease and left ventricular dysfunction: implications for the role of myocardial viability assessment in management decisions. J Thorac Cardiovasc Surg 1998; 116: 997-1004. 


\section{ORIGINAL ARTICLE}

4. Oldham HN Jr, Kong Y, Bartel AG, et al. Risk factors in coronary artery bypass surgery. Arch Surg 1972; 105: 918-23.

5. Elefteriades JA, Kron IL. CABG in advanced left ventricular dysfunction. In: Elefteriades JA, Lee FA, Letsou GV (eds). Cardiology clinics: Advanced treatment options for the failing left ventricle. Philadelphia: WS Saunders Company, 1995; 35-45.

6. Bounous EP, Mark DB, Pollock BK et al. Surgical survival benefits for coronary disease patients with left ventricular dysfunction. Circulation 1998; 78: 151-157.

7. Luciani GB, Faggian G, Razzolini R, Livi U, Bortolotti U, Mazzucco A. Severe ischemic left ventricular failure: coronary operation or heart transplantation? Ann Thorac Surg 1993; 55: 71923.

8. Louie HW, Laks H, Milgalter E, et al. Ischemic cardiomyopathy: criteria for coronary revascularization and cardiac transplantation. Circulation 1991; 84(Suppl 3): 290-5.

9. Alderman E, Fisher LD, Litwin P, et al. Results of coronary artery surgery in patients with poor left ventricular function (CASS). Circulation 1983; 4: 785-95.

10. Islamoglu F, Apaydin AZ, Ozbaran M, Yüksel M, Telli A, Durmaz I. Predictors of outcome after coronary bypass surgery in patients with left ventricular dysfunction. Anadolu Kardiyol Derg. 2002 Mar; 2(1):26-34.

11. Gatti G, Maschietto L, Dell'Angela L, Benussi B, Forti G, Dreas L, Soso P, Russo M, Sinagra G, Pappalardo A. Predictors of immediate and long-term outcomes of coronary bypass surgery in patients with left ventricular dysfunction. Heart Vessels. 2015 Jul 15.

12. Trachiotis GD, Weintraub WS, Johnston TS, Jones EL, Guyton RA, Craver JM. Coronary artery bypass grafting in patients with advanced left ventricular dysfunction. Ann Thorac Surg 1998; 66: 1632-9.

13. Mickleborough LL, Carson S, Tamariz M, Ivanov J. Results of revascularization in patients with severe left ventricular dysfunction. J Thorac Cardiovasc Surg 2000; 119: 550-7.

14. Argenziano M, Spotnitz HM, Whang W, Bigger JT, Parides M, Rose EA. Risk stratification for coronary bypass surgery in patients with left ventricular dysfunction-Analysis of the coronary artery bypass grafting patch trial database. Circulation 1999; 100: 119-24. 


\section{ORIGINAL ARTICLE}

\begin{tabular}{|c|c|}
\hline & $\mathbf{n = 1 0 2}$ \\
\hline Male & $84.3 \% \mathrm{n}=86$ \\
Female & $15.7 \% \mathrm{n}=16$ \\
\hline Diabetes mellitus & $48 \%$ \\
\hline Smoker & $84 \%$ \\
\hline Hypertension & $54 \%$ \\
\hline Diabetes +hypertension + smoker 36\% \\
\hline Stroke (recovered) & $1.8 \%$ \\
\hline Renal dysfunction & $0.9 \%$ \\
\hline Heart block & $0.9 \%$ \\
\hline Mitral valve regurgitation & $0.9 \%$ \\
\hline Mild & $22.5 \%(23)$ \\
Moderate & $15.7 \%(16)$ \\
Severe & $1.9 \%(2)$ \\
\hline
\end{tabular}

Table 1: Demography and preoperative characteristics of patients

\begin{tabular}{|c|c|}
\hline Peri-operative MI & Nil \\
\hline Bleeding & $2(1.9 \%)$ \\
\hline Post-operative renal dysfunction & Nil \\
\hline Inotropic support <24 hour & $69 \%$ \\
\hline$>24$ hour & $31 \%$ \\
\hline Mean ICU stay & $3 \pm 1$ days \\
\hline Mean postoperative hospital stay & $9.2 \pm 8$ days \\
\hline Atrial fibrillation & $18.6 \%$ \\
\hline Death & Nil \\
\hline Table 2: Post-Operative Outcome \\
\hline \multicolumn{2}{|c|}{}
\end{tabular}

\begin{tabular}{|c|c|c|}
\hline & Pre-operative & Post-operative \\
\hline Angina & & \\
\hline Mean Ejection fraction & $27 \pm 2.66$ & $35.3 \pm 3(\mathrm{p}<0.005)$ \\
\hline NYHA class I/II & nil & $92 \%$ \\
\hline III/IV & $100 \%$ & $8 \%(\mathrm{p}<0.005)$ \\
\hline $\begin{array}{r}\text { Table 3: Pre and Post-operative comparison } \\
\text { of ejection fraction and angina }\end{array}$ \\
\hline
\end{tabular}




\section{ORIGINAL ARTICLE}
AUTHORS:
1. Murtaza A. Chishti
2. Ajay Meena
3. Gaurav Goyal
4. Premraj Nagarwal
5. Varun Chhabra
6. Ashish Jain
7. Deepesh Aggarwal
8. Ramanand D. Sinha

\section{PARTICULARS OF CONTRIBUTORS:}

1. Assistant Professor, Department of Cardiothoracic and Vascular Surgery, Mahatma Gandhi University of Medical Sciences and Technology, Jaipur.

2. Assistant Professor, Department of Cardiothoracic and Vascular Surgery, Mahatma Gandhi University of Medical Sciences and Technology, Jaipur.

3. Assistant Professor, Department of Cardiology, Mahatma Gandhi University of Medical Sciences and Technology, Jaipur.

4. Assistant Professor, Department of Cardiology, Mahatma Gandhi University of Medical Sciences and Technology, Jaipur.

\section{FINANCIAL OR OTHER} COMPETING INTERESTS: None
5. Assistant Professor, Department of Cardiology, Mahatma Gandhi University of Medical Sciences and Technology, Jaipur.

6. Senior Resident, Department of Cardiac Anesthesia, Mahatma Gandhi University of Medical Sciences and Technology, Jaipur.

7. Assistant Professor, Department of Cardiology, Mahatma Gandhi University of Medical Sciences and Technology, Jaipur.

8. Assistant Professor, Department of Cardiology, Mahatma Gandhi University of Medical Sciences and Technology, Jaipur.

\section{NAME ADDRESS EMAIL ID OF THE CORRESPONDING AUTHOR:}

Dr. Murtaza A. Chisti,

Assistant Professor,

Department of Cardiothoracic and

Vascular Surgery,

Mahatma Gandhi University of Medical

Sciences and Technology, Jaipur.

E-mail: cmurtazaa@gmail.com

Date of Submission: 03/10/2015.

Date of Peer Review: 04/10/2015.

Date of Acceptance: 16/10/2015.

Date of Publishing: 26/10/2015. 